\title{
LEADING WAYS: \\ Preliminary Research \\ on LEF Leadership for the \\ Public Education Network
}

\author{
JACQUELINE RAPHAEL \\ ALISSA ANDERSON \\ DECEMBER 12, 2002

\section{URBAN INSTITUTE}

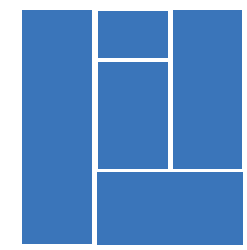




\section{LEADING WAYS: Preliminary Research on LEF Leadership for the Public Education Network}

Public Education Network

Office of Research \& Evaluation 601 Thirteenth Street NW, Suite 900 North Washington, DC 20005 2026287460
Urban Institute Education Policy Center 2100 M Street NW

Washington, DC 20037 2028337200 



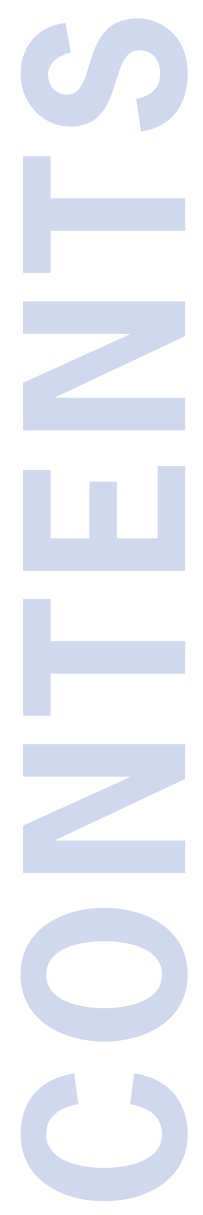

5 Executive Summary

7 Background on Local Education Funds

7 Defining a Research Agenda for the Study of LEF Leadership

8 Executive Director Survey

8 Table I: Founding Directors Interviewed

9 Interviews with Founders

9 Themes Emerging from the Research:

Creating a Space for Sustained Collaboration in Communities

10 Who are the Leaders?

11 What Strategies Were Employed by LEF Leaders?

14 What Methods Describe the LEF Leaders' Brand of Leadership?

14 Adaptive Leadership

16 Relationship-building

16 How Did PEN Facilitate LEF Development?

17 Implications of Research Themes for the Study of LEF Leadership

17 The Environment in Which LEF Leadership Emerges

18 Figure I:The Environment in Which LEF leadership Emerges

19 Suggestions for Future Research

22 Bibliography

23 Appendix A: Founding Director Interview Summaries

23 Charlotte Advocates for Education

24 Forward in the Fifth

25 Lincoln Public School Foundation

26 Los Angeles Educational Partnership

27 Mon Valley Education Consortium

28 Nashville Public Education Foundation

29 Paterson Education Foundation Inc.

30 Portland Schools Foundation

32 Public Education and Business Coalition

32 Washington Parent Group Fund

33 Appendix B: Founding Director Telephone Interview Protocol

33 I. Founding and Early Years of LEF

34 II. LEF Organizational Issues

34 III. LEF Context

35 IV. Background of Respondent

35 V. Questions about Research Methods 



\section{EXECUTIVE SUMMARY}

In the early 1980s, public schools, particularly in urban areas, were struggling with changing demographics and a need for greater community commitment to public education. Small independent community-based organizations, called local education funds (LEFs), were first established at this time by community leaders to bridge the gap between communities and their schools. Twenty years later, the Public Education Network (PEN), the national organization of more than 70 of the country's LEFs, is championing LEFs' unique contributions to educational reform and planning new methods to continue to support their work. One important aspect of PEN's efforts is the development of a research agenda around LEF leadership and effectiveness.

The Urban Institute has supported the emerging research on LEF leadership in several ways. First, in 2001, researchers administered and analyzed results of a survey of all current LEF executive directors. The results provided a snapshot of leadership characteristics and attitudes. Second, in 2002, researchers reviewed existing literature on LEFs and nonprofit leadership and interviewed several individuals about the founding of LEFs. Third, also in 2002, researchers conducted 60to 90-minute telephone interviews with 10 founding directors of early LEFs.

This report describes efforts by the Urban Institute and PEN to better understand and describe leadership in LEFs. The research conducted to date reveals the following common features of LEF leadership:

LEF leaders create a space for sustained collaboration in communities. Founders, in particular, see their work as establishing unique and lasting forums in their communities.

LEF leadership fits well in an adaptive leadership framework, in which the director educates him or herself about community values and exposes issues that must be resolved through collaborative action. Adaptive leaders mobilize others around a community consensus rather than dictate a solution. In the case of LEFs, developing key relationships contributes to successful leadership. These relationships involve community members, principals, government officials, local businesses, and other stakeholders. Because LEFs are meant to provide a permanent venue for collaboration, these relationships are not only instrumental but also ends in themselves.

Although LEF leaders are extremely invested in their communities in terms of socioeconomic status and race, they are not typically representative of the communities their LEFs serve. This gap in constituency and representation leads to uncertainty about whether LEFs effectively engage all segments of the community in their work. More inclusive leadership, then, is an issue worth exploring.

\section{LEF leadership appears to involve making strategic choices in an environment of} constraints. With limited human and financial resources, LEFs must attempt to achieve their goals through a complex interaction with their communities and schools. Key stages in LEF development include the shift to greater community engagement and systemic reform. However, not all LEFs follow the same developmental pattern. 
The report recommends a two-pronged approach to future studies of LEF leadership. Because preliminary research has already yielded useful themes to pursue, a small number of initial case studies about early founders is suggested.The story of founders' experiences, told through their own and their community's perspective, is a rich source of information that will allow for in-depth examination of the complex nature of LEF leadership. These initial case studies should be accompanied by a broader data collection activity, such as a survey of all current directors, to expand on findings from the first survey and to test themes emerging from the case studies. A survey instrument could also be used to identify other areas of interest, such as "next-generation" leaders, for subsequent studies of LEF leadership. Results from a wellplanned research agenda, involving both sources of information, would serve as a valuable guide for PEN's future organizational development efforts. 


\section{Background on Local Education Funds}

Local education funds (LEFs) began to emerge at a time when public schools, particularly in urban areas, were grappling with the complex challenges of a shifting sociopolitical environment. After a decade of recession and deindustrialization, many communities faced increased poverty and dire social problems. Middle-class flight from cities left lower-income people, especially poor people of color, increasingly isolated. Consequently, when public schools desperately needed more resources to serve students with greater needs, they were left with an eroded tax base from which to draw funding.

While the crisis in public education had been building throughout the 1970s, it did not receive widespread national attention until the publication of $A$ Nation at Risk in 1983 by the National Commission on Excellence in Education. This report accused the nation of committing an act of "educational disarmament," claiming that the deterioration of public education posed a risk to American industry, democracy, and social progress. It reminded the nation that all citizens have an obligation to promote educational excellence for U.S. students.

It was in this context in 1983 that the Ford Foundation, along with others, created the Public Education Fund (PEF). ${ }^{1}$ By providing seed grants, PEF fostered the development of many of the first LEFs in communities across the country. Leaders of these organizations began to mobilize parents, local business and corporate leaders, politicians, and others to improve their local public education systems. Establishing an organization that brought together stakeholders who had not collaborated previously required a special kind of leader. It is this leadership model, which applies to LEFs as unique intermediary organizations, that is of interest to the Public Education Network (PEN), a national organization that developed from PEF in the late 1980s to connect and amplify the work of LEFs across the country. Starting in 2001, PEN began working with researchers to better understand and describe such a leadership model.This report describes efforts by PEN and the Urban Institute to engage in this investigation.

\section{Defining a Research Agenda for the Study of LEF Leadership}

Over the last 20 years, PEN and its predecessor organization, PEF, have played a major role in starting, promoting, convening, and nurturing LEFs. Currently, PEN is also engaging in theory-building activities, including describing its own theory of action. As part of this theory-building, the organization has begun to define a research agenda that will contribute practically to PEN's efforts to support LEFs, build a body of knowledge about the work of LEFs and their impact on communities and schools, and contribute more broadly to an understanding of the efforts of communitybased intermediary organizations in influencing education reform.

In 1998, PEN commissioned From the Margins to the Center of School Reform:A Look at the Work of Local Education Funds in Seventeen Communities (Useem 1999), a foundational study that systemically describes the work of LEFs, including LEF organizational characteristics, core activities, and conditions for effective work. The report concludes that the LEFs' capacity for improving student outcomes depends on the skill of their board of directors and executive directors, particularly because most LEFs are "lean," with a comparatively small staff in light of their ambitious missions. The author writes that, "While resilient, the LEFs also remain fragile. It would be wise for future research to focus on the 
ways [LEFs] cope with internal organizational challenges," particularly the demands placed on LEF leaders. Their greatest demands, the report notes, include coping with a shrunken funding landscape for nonprofits; motivating and retaining underpaid staff; and responding constructively to the idiosyncrasies of bureaucratic school districts, the politics of urban schools, and the challenges of supporting schools in serving a rapidly changing student population (pp. 28-29).

In its initial conversations with the Urban Institute, PEN framed its current approach to leadership around three important subgroups that could be studied in the future:

Founding directors, who founded, or were the first directors of, early LEFs established in the 1980s. The experiences of these directors reveal much about the roots of the LEF movement and are an important piece of LEF history. Some of these early founders have remained in their leadership positions for many years and offer an opportunity to study their ability to adapt to a changing environment.

Transitioning directors, who have taken over from founding directors. The challenge of succeeding a founding director, often a visionary, is a rich area of study. Having a better understanding of succession would contribute to several fields of inquiry and help PEN in its efforts to support these directors.

New or "next-generation" executive directors, who lead LEFs that were created in a wholly different environment regarding education reform, accountability, and community involvement than their forerunners.

Urban Institute researchers reviewed

\begin{tabular}{llr} 
Local Education Fund & Location & Founding Year \\
Washington Parent Group Fund & Washington, DC & 1981 \\
\hline Mon Valley Education Consortium & McKeesport, Pennsylvania & 1983 \\
\hline Paterson Education Foundation, Inc. & Paterson, New Jersey & 1983 \\
\hline Los Angeles Educational Partnership & Los Angeles, California & 1984 \\
\hline Public Education and Business Coalition & Denver, Colorado & 1984 \\
\hline Forward in the Fifth & Berea, Kentucky & 1986 \\
\hline Nashville Public Education Foundation & Nashville, Tennessee & 1987 \\
\hline Lincoln Public School Foundation & Lincoln, Nebraska & 1989 \\
\hline Charlotte Advocates for Education & Charlotte, North Carolina & 1991 \\
\hline Portland Schools Foundation & Portland, Oregon & 1994 \\
\hline
\end{tabular}

Table I: Founding Directors Interviewed

\section{Executive Director Survey}

The first effort, a survey administered to current directors of 59 LEFs in PEN in June 2001, ${ }^{2}$ examined the roles and responsibilities of current LEF executive directors in order to lay a foundation for a more complex study of LEF leadership. Although PEN conducts an annual LEF survey of current directors, little systematic data has been collected on individual leaders. The results provide a snapshot of leadership characteristics and attitudes, as well as contextual information about LEFs and communities. ${ }^{3}$ The development of the survey was informed by literature on leadership including Chrislip and Larson (1994) and Nanus and Dobbs (1999). A key finding emerging from this study is the perceived value of (and need for more) strategic planning among LEF leaders. Executive directors reported spending more time managing programs than they would have liked.Though this predicament is not uncommon for small 
nonprofits with few staff, the implications of the gap between needs and actions is an important area for future study. Survey results did not specify exactly what respondents meant by "strategic planning." What would strategic planning accomplish, and what would it allow LEFs to do differently?

Other findings included differences in background and experience that exist between new (in their position for four years or less) and longer-term directors, including a decreased likelihood of new directors to live in the community served by their LEF. Whether this finding is a result of changing demographics in cities needs to be explored further.

\section{Interviews with Founders}

The second data collection activity included telephone interviews, conducted in July and August 2002, with founders of early LEFs. ${ }^{4}$ These interviews explored the context in which LEFs were founded and the types of activities in which their leaders initially engaged. Conceived as a planning activity for in-depth case studies of early longstanding LEFs and the leaders who shaped the organizations, this study was designed to produce themes for subsequent research.

To prepare for these interviews, the researchers reviewed literature on LEFs, including Useem (1999), Bergholz (1992), and Puriefoy (2001), as well as individual LEF reports archived by PEN. They also explored the concept of "adaptive leadership" developed in Heifetz (1994). The researchers interviewed several individuals about the early LEF founders, including David Bergholz, who established LEFs around the nation as part of his role with PEF; Paul Reville, a founding director of an early LEF now on PEN's board of directors and research committee; and Marge Hiller, a founding director of an early LEF and a PEN board member. These interviews, and the review of literature, provided a context to help researchers develop and refine questions to be asked of LEF directors.

The researchers then received from PEN a list of 21 founding LEF directors, most of whom started their LEFs in the 1980s. The researchers called directors to ask them each to participate in a 60- to 90-minute telephone interview. The final selection of 10 founders (Table I) resulted in a fairly diverse representation of LEFs by geographic location, founding year, and size. ${ }^{5}$ Researchers conducted the interviews using a semi-structured interview protocol. ${ }^{6}$

\section{Themes Emerging from the Research: Creating a space for sustained collaboration in communities}

From the results of the executive director survey, the review of earlier research, and the telephone interviews with early founders, several research themes about LEF leadership have emerged. ${ }^{7}$

Consistently, founders talked in interviews about their LEF as the first organization of its kind in their community that brought together a wide range of stakeholders around education reform. They claimed that no such venue or foruminformal or formal-existed previously, and the education system lacked the will and/or the capacity to elicit broad support. (Whether this is accurate could be a topic for future research.) Everyone had a right to be "at the table," in the words of one founder, but first, the "table" had to be built. An overall theme, then, of creating a space for sustained collaboration in communities, summarizes the role of these early LEF leaders as they viewed themselves. They saw their 
job as carving out a space in their communities in which stakeholders, who had not worked together previously, could collaborate to improve public education. This job differed from creating a new watchdog or service organization; those organizations can achieve their purpose by securing experts to perform specific tasks. Creating an LEF involved building a new vehicle for community involvement and change, which meant creating new relationships in the community.

Not only did LEF founders seek to establish a unique entity in their communities, but they also sought to bridge the gap between schools and the community by building a lasting bridge. Unlike some mission-based organizations, the LEF would not close its doors once its goals were achieved. As one LEF founder put it, "What we did from Day One was think about what our legacy would be. We wanted to leave something behind. We felt that it was very important that public education and learning should hold a premier place of importance in every community that our organization touched." For most LEFs, this meant staying in business as long as schools were in business.

Below are questions that explore issues related to the overall theme of creating a space for sustained collaboration. This discussion begins with the individuals who fulfilled a leadership role, describes the strategies employed by LEF leaders, explains features of the particular brand of leadership they exercised, and ends with a brief description of key ways in which PEN facilitated LEF development.

\section{Who are the Leaders?}

LEF executive directors, and particularly founders of early LEFs, are a fairly homogenous group. Results from the executive director survey suggest that current directors tend to be white, female, and highly educated. Slightly more new executive directors are male, but the great majority (74 percent) are female. The executive director survey and telephone interviews with founders did not gather information on income. Comments from founders, however, suggest that many were financially secure at the time of their LEF's start, allowing them to donate large amounts of time to their work. For example, many of the founders became involved with LEFs as part of their reentry into the workforce after raising children.

Early LEF founders were engaged in community politics through local political organizations, such as the League of Women Voters. Many had also been involved in local schools, not typically as an educator, but as a volunteer leader, such as a PTA president. Yet the executive director survey reveals fewer recent directors reported living in the communities that are directly served by their LEFs, a trend that needs to be analyzed more thoroughly to understand its significance.

To create new and unique conversations and partnerships within their communities, founders possessed distinctive capabilities. They were able to accomplish many start-up tasks, such as raising funds, engaging stakeholders, establishing relationships with the school system and schools, and talking to the media. Many founders worked closely with board members or other community leaders to accomplish these tasks. But whether they did all these tasks themselves-the "jack of all trades," according to David Bergholz-or with colleagues, the founders had to be capable of managing a startup. They either created the vision that would guide the new LEF, or someone, such as a board of directors, trusted them to take on this role. According to Bergholz, the founders were active, tough-minded, focused, and capable of "making things happen." One founder agreed that being able to keep the focus in mind is critical to being an LEF director because so many people-parents, teachers, community members-approach the director thinking only of their own personal concerns. The director has to be able to weigh these concerns and derive feasible solutions for complex problems. 
LEF founders were perceived as extremely reliable people. They were seen as trustworthy, credible, and not "out for themselves." When asked what they felt qualified them to serve as founding leaders, LEF founders acknowledged that it was critical to their success that they be viewed as "fair" and "objective" by key players-echoing responses from the background interviews. LEF founders tended to be good listeners and communicators and felt these skills were critical to their leadership. Some-though not all-of the founders eschewed taking "center stage" in the organization and in the community, giving their board members the lion's share of credit for LEF successes and creating collaborative efforts with schools and other organizations rather than tackling large projects on their own. Founders also had to carefully carve out the LEF's role in an environment with multiple bureaucratic players. Knowing whose responsibilities not to assume, such as those of the Board of Education, was important to founders. Whether this leadership style is related to the founders' gender might be of interest in future research.

LEF founders had to maintain high levels of energy and enthusiasm for public school reform-a challenge, they said, because of the "fuzzy" and "intangible" nature of school reform issues. Change occurs slowly in education, making it difficult to keep a board of directors and other stakeholders inspired over time. Founders also have to persuade community members that education, with its tax funding base, needs their financial support.

Finally, LEF leaders are extremely invested in their work. They tackle significant challenges, and make great personal sacrifices, because of their commitment to the LEF. Indeed, the 2001 survey indicates that current executive directors are spending an average of 52 hours per week in their jobs, despite fairly low salaries. At the same time, not a single current executive director reported being dissatisfied with his or her job.

Such a great degree of investment can cause difficulties over the long haul, however. Several founding directors alluded to stresses associated with LEF leadership. One founder admitted being unsure how much longer she could continue in her position because of the stresses, frustrations, and excruciatingly slow pace of change. In a more extreme case, another founder said the work had affected her health, leading her to take a hiatus and ultimately leave the job. Future research can identify ways that LEF leaders maximize organizational capacity given limited resources and the high levels of investment that this work demands.

In most cases, the board of directors comprises a key feature of LEF leadership. PEN survey data, ${ }^{8}$ summarized in the report of executive director survey results, suggest that board members, too, are a relatively homogenous group: 63 percent are male and 78 percent are white. Furthermore, only 57 percent of executive directors surveyed felt that their board of directors was representative of the community it served, though they rated their boards highly in other areas. However, the interviews with directors suggest that boards may be becoming more inclusive. One director said, for instance, "The younger leadership that we brought to the board...is more diverse than ever. It has learned to talk about race and class issues more openly and moved the conversation to other venues than our board meetings."

\section{What Strategies Were Employed by LEF Leaders?}

Wendy Puriefoy's characterization of LEFs as "small organizations with big missions" is borne out by several sources, including Useem (1999), who describes LEFs as "lean" in terms of staff and resources, yet innovative and unafraid of controversy (p. 8). PEN survey data, summarized in the executive director survey report, reveal that half the LEFs in 2000 had a staff of six or less, of which two members, on average, were part-time staff members. The leaders' awareness that 
their missions are large and complex is reflected in a finding from the executive director survey: Executive directors on average reported that although strategic planning is the activity on which ideally they would like to spend the most time, relative to other activities, it is the activity on which they spend the least amount of time. Directors are spending more time than they wish on managing programs and fundraising, a reflection of the challenges they face as small nonprofit organizations.

Indeed, LEF founders faced a challenging task in creating a space in their communities for collaboration around education. In the 1980s, when the early LEFs began, their founders were trying to build consensus around an issue that had only begun to be perceived as a "public" concern. A Nation at Risk and other reports on education published in this period suggested that public education had to be "fixed." But the public, including the business community, had not taken the reins previously. And because LEF founders were seeking a broad consensus across a full range of stakeholders, the job was doubly difficult. Certainly, any community-based organization bringing multiple players together around an issue will face challenges. But LEFs sought to bring everyone to the table, including stakeholders who had not collaborated before. Such a high level of collaboration increased the number of discussions, flyers, ideas, and dollars needed to do the job well.

Despite these constraints, LEF leaders are compelled to think strategically about how to accomplish their goals. As stated in Useem (1999), "Boards of directors and LEF staff wrestle constantly with questions of strategy, trying to figure out how to target their time and money in order to leverage their broadest long-term impact on educational practices and policies" (pp. 26-27). These strategic decisions involve external and internal events, and urgencies originating in state or local legislation, judicial settings, and other arenas. Important points in the developmental growth of LEFs included the following:

The use of teacher mini-grants. Repeatedly, founders indicated that the teacher mini-grant program was an important first step to developing a working relationship with schools and districts. One founder said she created her LEF's "foundation" through this work, as the program produced tangible benefits and was very popular in schools. In Mon Valley, the popularity of the mini-grant program in one district led 19 other district superintendents to contact the founder about participation, a clear indication of the power of the program. In addition, succeeding at other programs, such as those discussed above, also developed the LEF's visibility and credibility.

There was hardly anything

going on in the community in

terms of redevelopment

efforts...[so] new and unique conversations and partnerships had to be created.

- a longstanding LEF executive director

Information dissemination to the public. Many LEFs took on this role early in their history. Forward in the Fifth, for example, tackled the job of explaining the Kentucky Education Reform Act to the local public. Several LEFs explained procedural issues, such as what a school board does and how a school or district budget works. More complex issues were also tackled. In 1999, the Paterson Education Fund tried to influence policy by conducting "conversations" about race and education with 150 people from the city. Notes from these talks were used to draw up a community-wide agenda for change that the Fund actively promotes. 
Implementing projects in schools. Most LEFs provide services to schools and/or districts, typically involving staff development, community/school collaborations, and between-school/district-wide initiatives. Several founders described projects that could be considered prototypes for reforms currently popular in education. For example, Mon Valley Education Consortium replied to a request for proposals issued by the state to develop cadres of lead teachers in area schools. Mon Valley's response to the request for proposals was unique among the seven sites funded.The LEF program required school staff consensus on the selection of teacher leaders, rather than having the principal choose them, and called for schools to devise their own goals and agenda rather than following a plan drawn up by outsiders. These features are key to many current whole-school reform models. Similarly, the Public Education and Business Coalition used collaborative teams, made up of university experts and teachers, to plan and deliver professional development to area schools-another model currently used to improve staff development. The LEF also involved local schools and the Colorado Outward Bound School in the development of a K-12 school of choice, another option gaining popularity. The Comprehensive Health Centers program promoted by PEN may also have produced precursors to current community school models, though this was not discussed in interviews with founders.

In addition to these similarities, some themes distinguish LEFs and demonstrate how no one "story" or progression can describe all LEFs adequately:

Incorporating bottom-up and top-down approaches. Nearly all LEFs do some work "in the trenches" helping schools develop capacity, but as their LEFs grew, some founders found it necessary to begin dealing with the school district system. "If an LEF wants to be serious about the vision of highperforming schools for all kids, it has to be mindful of district conditions and leadership," said the Portland founder. "You're pushing a very big boulder up a very big mountain if you do it outside in. I don't think this work is effective without district coherence and leadership." Denver's founder agreed: "If you don't have a high-level district person involved, you can end up just banging your head against the wall."

Shifting toward greater community engagement. Most, but not all, LEFs evolve toward a greater community engagement role. Charlotte, founded in 1991, did so more quickly than most.To address a crucial school board election issue that arose early in its development, the LEF found itself launching a major public information campaign designed to catalyze the community. Factors that contributed to this early effort included mentoring received directly from PEN, good financial support from its inception, a strong board willing to tackle tough issues, and a supportive superintendent. Other LEFs made this shift well after they had been launched. Paterson's initial years were relatively traditional, for example, but state takeover of the district in 1991 thrust the LEF into a much more politicized environment. Though the board was reluctant to take this route, the founder helped board members see that they had to get involved to become a key player in local education. The Los Angeles Educational Partnership also developed along these lines to become a well-rounded organization that is fairly independent of the school district. Contributing factors included an excellent referral of large funding streams to the LEF by PEF and a superintendent who stressed the importance of the LEF's independence. 
Yet not all LEFs have made the shift to full community engagement. Two founders described ongoing challenges to this shift related to the different priorities held by LEFs and school superintendents. Furthermore, not all LEFs are headed in this direction. The Washington Parent Group Fund has stayed true to its mission that focuses on parent training, with little change. Other LEFs appear to prefer acting only with clear district support.

Making the transition to systemic reform. At least half of the founders interviewed discussed a shift from teacher mini-grants and other "niche-filling" activities to more systemic education reform activities through large-scale initiatives that changed how schools and districts operated. Most credited the large PEN grants-Library Power and the Comprehensive School Health Initiative-as a major force in developing the LEF's ability to do so. For example, a Library Power grant allowed the Nashville Public Education Fund to foster more systemic, district-wide change through the adoption of best practice recommendations for the district's schools.

Carving out turf. In some communities, LEFs have to work with other organizations to negotiate their roles. The Nashville Public Education Foundation, for example, collaborates with other organizations and will respect other organizations' turf. For example, the LEF did not send volunteers into schools because another organization played this role. This type of coordination allows community-wide efforts to thrive. But in some LEFs, these turf issues presented challenges, such as the creation of tensions with another city group.

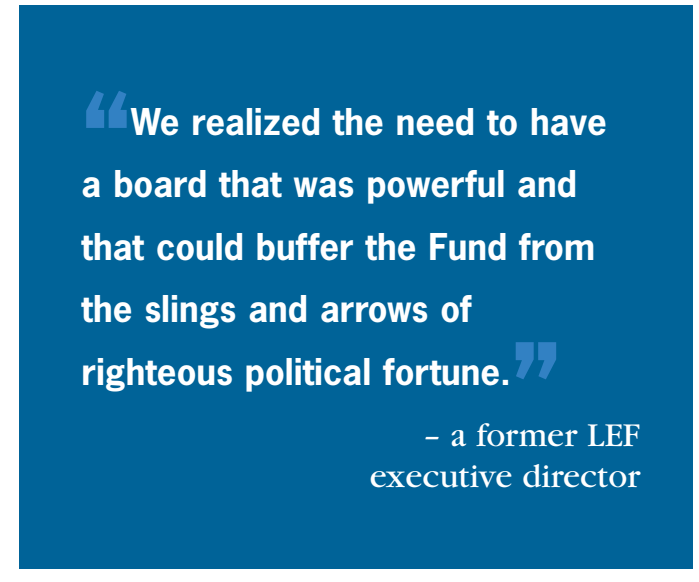

These themes suggest that certain key shifts occur across the lifetime of individual LEFs. Many of these are related to creative tensions at the core of the LEF vision, including the tension between programming and policy, between dealing with individual schools and with the school system, and between "critical" and "friend" in the "critical friend" relationship LEFs nurture with school districts.

\section{What Methods Describe the LEF Leaders' Brand of Leadership?}

\section{Adaptive Leadership}

The executive director survey results suggested that LEF leadership could best be described by a collaborative model. As described by Chrislip and Larson (1994), this model emphasizes the leader's focus on the process of bringing together his or her constituents to solve problems. This model can be enriched by applying the concept of "adaptive leadership," as described by Heifetz (1994). Unlike technical leadership, which involves solving routine problems, adaptive leadership confronts problems that demand learning and innovation from leaders. In adaptive leadership, "the leader is not at the forefront" but, rather, works to enlist the community in addressing its own problems. Adaptive leaders learn about the values held by their community and expose conflicts between community values and the current reality in order to incite action.

The early LEFs emerged at a time when few people were thinking about the community's role in improving public 
education. LEF founders had to build the case for public engagement in this arena. Early founders clearly saw that schools were in need of greater support. Nearly all shared the same broad goal: bridging the gap between schools and community. But rather than dictating a solution, the founders turned to their community for help. Most founders indicated in interviews that they did not know, initially, what specific objectives and activities should be undertaken to achieve their broad goal. But even if they had known, their predisposition to consensus suggests they would not have acted independently. These leaders would seek evidence that their agenda reflected community values and needs, as they were committed to defining a mission that could be owned by their communities. To do so, founders undertook some of the following activities:

Listening carefully to a range of community concerns. The Portland Education Foundation founder's first activity was to ask 100 community leaders what they felt were the schools' major challenges and bring this information back to her board of directors. The founder observed that this activity also served to inform community members about the new LEF. Similarly, the founder of the Mon Valley Education Consortium picked up her telephone and began polling community members about their views on public education. The founder of the Public Education and Business Coalition in Denver, who conducted focus groups with community members soon after launching the LEF, said, "We had no original plan. We set the LEF up initially to listen and learn what could be done."

Asking school/district staff where they needed belp. Forward in the Fifth's first activity was to convene the superintendents of its multiple districts and ask them how the LEF could help them. The founder said she knew she would have to take action on whatever they discussed, as this would be the quickest, most effective way to establish a common agenda among district superintendents from 27 counties. Denver's founder brought business and central office leaders together to find out what skills local graduates lacked, and then the LEF designed a staff development program to address that need. Similarly, one of the first projects of the LEF in Charlotte was to provide professional development to increase the number of students in pre-algebra, a priority voiced by the superintendent at an LEF board meeting.

Rallying around existing issues. Several founders described specific issues that shaped their initial mobilization efforts. Forward in the Fifth was created in response to a report that revealed the fifth congressional district in Kentucky was ranked last nationally for high school graduation by adults. The Mon Valley Education Consortium sprang up when drastic economic decline in the region threatened the resource base for schools. The Portland Education Foundation emerged in the early 1990s, when the bar for school performance was raised significantly by the legislature and funds for education were cut dramatically by a local property tax initiative.

In one form or another, most founders consulted a variety of stakeholders in the community to stimulate dialogue and elicit a baseline response to education issues. Viewed from the perspective of adaptive leadership, this strategy is critical to success. Because communities are naturally composed of diverse values, adaptive leaders must weigh "competing value perspectives."This requires a leader who is open and fair. As discussed earlier, many early founders reported being perceived this way by their community. 
One issue not probed systematically in either the interviews with founders nor in the executive director survey is how well LEF leaders include all sectors of their communities in their collaborative process. However, a former LEF director said,"When I look back on our early organizing efforts, [I realize] we were organizing middle-class white parents. Now...we recognize the need to reach the lower class in order to break the cycle of dropouts." Both the extent of community involvement (e.g., numbers of community members attending at meetings), and the representativeness of that involvement (e.g., presence of traditionally underrepresented groups), are issues that require further study.

\section{Relationship-building}

The concept of adaptive leadership is personified by a leader who mobilizes others to tackle difficult problems themselves rather than trying to get them to follow his or her vision. To accomplish this, founders demonstrated an almost extreme focus on building relationships that would last. This activity in and of itself is valued by LEF leaders, including founders and current directors.

Every interviewed founder spoke at length about the importance of building a good collaborative relationship with school districts and schools. Since greater collaboration is a core feature of the LEFs' mission, almost all of their early programs and activities could be viewed as relationship-building. Building close district relations while maintaining independence was an ever-present challenge for founders. To foster this relationship, founders emphasized the importance of appearing "non-threatening," with "good intentions," and open to "having an honest dialogue." In addition, the LEF itself developed new relationships: Several LEF founders spoke proudly of how their board of directors brought together people who had never talked before, such as the presidents of the teachers' union and of local corporations.

The need to build good relations with school and district personnel and the community at large was echoed in the executive director survey, in which almost 40 percent of respondents cited interpersonal/communication skills and relationship building as the most important skills a director could possess. Executive directors also reported that out of eight possible activities, establishing and maintaining district relations was the one on which they spent the most time.

Building relationships is important within LEFs as well. Our interviews with founding directors suggest that many forged truly collaborative working relationships with board members. Additionally, 79 percent of current executive directors surveyed indicate that their board "challenges them in productive ways."

\section{How Did PEN Facilitate LEF Development?}

While early LEFs faced numerous start-up challenges, many were fortunate to receive financial support from the PEF. Through funding from Ford and other national foundations, PEF provided an initial seed grant to many early LEFs. These small grants enabled founders to leverage matching funds and expand their organizations.

Starting in the early 1990s, PEN continued to assist LEFs by making available large grants (e.g., Library Power) that benefited them in many ways. First, the grants helped LEFs gain authority, including the attention of central office administrators. One founder noted that in her first meeting with the district's new superintendent, she had a \$1.2 million Library Power grant

“in my pocket." Another director indicated that the Library Power grant, particularly the activities it involved, helped her LEF gain a higher profile in the community. To this day, her LEF is considered the authority on libraries. Second, large PEN grants 
were a major force in developing LEFs' ability to move toward more systemic approaches to education reform. While many founders acknowledged an early desire to move toward systemic change, they often cited PEN grants as the catalyst in carrying out such change. Through PEN grants, LEFs provided funds to schools, but with those funds came various program requirements (opportunities or obligations, depending on buy-in), such as participation in training, collaborative initiatives, data collection, and other activities that support educational change.

Finally, PEF and PEN leaders such as David Bergholz, Gerri Kay, and Wendy Puriefoy provided many leaders with advice and technical assistance. These individuals were critical to developing the missions and programs of some LEFs. Furthermore, due in large part to guidance from PEF/PEN, most of the early LEF founders worked with boards of directors that included high-powered corporate and political decisionmakers. These "power" boards provided not only financial resources and valuable expertise, but also access to other important community members including funders and district officials. Moreover, board members' status in the community gave LEFs the credibility and legitimacy needed to carry out their work. The executive director survey findings reveal that LEF directors do talk to other LEF directors and to PEN, presumably for networking purposes. However, it may be useful to collect more detailed information from current directors about the range of activities that could be encouraged by PEN to assist LEFs.

\section{Implications of Research Themes for the Study of LEF Leadership}

\section{The Environment in Which LEF Leadership Emerges}

The research conducted on LEF leadership to date-the literature review, the survey of current executive directors, and the interviews with early founders-has focused on the tasks that LEF leaders undertake - their roles, responsibilities, successes, and challenges. It is our belief that leadership must be defined as a function of these actions, including the local and national context in which these activities take place. If we accept that LEF leaders are adaptive and collaborative, then features and shifts in the local, state, and national context will play a critical role in defining the work of LEF leaders. The way that an LEF adapts to its surrounding context, and vice versa, will form the fabric of LEF leadership.

A next step in thinking about LEF leadership would be to define the environment in which these and other leadership themes play out. Figure I, on the next page, is a preliminary attempt to capture this environment in a visual model.

As discussed, leadership is embedded in the context of an LEF. Any study of LEFs, no matter what the focus, ought to take into account the stage of organizational development of its subjects. Thus, the central circle in this model describes four traditional developmental stages of a successful organization: start-up, growth, establishment, and full institutionalization. ${ }^{9}$ Within each of the stages, we have identified four key LEF components that are influenced by LEF leadership: vision/mission, programs/policies, human capacity (e.g., director, staff), and financial capacity.

The extent or level of activity in each of these components will vary depending on the LEF's developmental stage. For example, an LEF in the startup stage would likely be focusing much energy on the definition of its mission. It may be managing only one or two projects, such as a teacher mini-grant program or a community dialogue to implement its mission. Human and financial resources would be limited. An LEF in the established stage will likely have a larger number 
of programs and policies, possibly with more emphasis on systemic reform and full community engagement. Staff will have been hired, the board of directors will have a different role than in startup, and financial resources probably will have increased.

Furthermore, the key components interact with each other. For example, as discussed in this report, financial and staffing constraints have had a major impact on the scope of LEF efforts. Many LEF directors struggle to identify consistent funding sources that will allow them to spend their time on programmatic and policy work. In response to an executive director survey item, one director wrote:"I am the only staff. This limits the number and type of projects our LEF can take on." It is important to document the challenges to LEFs and their leaders, particularly now, when funding for nonprofit organizations is limited.

Each LEF operates in a complex environment that is uniquely determined not only by the inner circle of the model, but also by the LEF's interactions with its local, state, and national contexts, represented by the two outer circles. These interactions work in both directions, by which we mean local, state, and national influences affect, and are affected by, the LEF's outputs and outcomes. (Similarly, local and state contexts are affected by and affect each other.) Interviews with founders revealed many instances in which the passage of local or state laws became the impetus for LEF action. Of course such action may not have been possible, had the LEF not created a space for collaborative work, built relationships between the schools and the community, demonstrated a willingness to work within the local context, and responded favorably to opportunities and obstacles along the way. Likewise, LEF actions have changed the local context. Interviews with founders provided many examples, such as reform initiatives in schools, passage of bonds, community actions to keep teachers on the payroll, and other advocacy efforts.

The complex contexts in which LEF leadership functions, as represented in Figure I, present a rich area for study. As described in this report, many LEFs have undergone shifts in their scope-from extremely supportive to more critical of a school district; from school-based to more systemic, district-wide education reform; and from programming to policymaking/information dissemination efforts. The reasons for these shifts are not readily apparent. Some shifts represent local, idiosyncratic responses to the education system within a community. Other shifts are likely to be responses to the passage of "No Child Left Behind" and the changing national environment of particularly heightened 
educational accountability. Still others may be the result of unexpected opportunities that LEFs-by creating a space for sustained collaboration-are poised to seize.

\section{Suggestions for Future Research}

How could PEN begin to illustrate the influence of LEF leadership in this environment? The research described in this report leads to many themes for future study, four of which are predominant across a range of LEF leadership experiences. Described below, these four research themes fit under the overall theme of creating a space for sustained collaborative leadership:

1. Adaptive leadership. Consistently, LEF leadership is described as a collaborative effort to develop a shared agenda unique to the local community. Leadership is predicated on learning, building consensus, and responding creatively to the context in which work is undertaken. As we have seen, LEF agenda items can arise as a result of internal reflection within the community (e.g., dialogue among community members) and of external events that impinge upon the community (e.g., community response to legislative action). Charting the ebb and flow between internal and external forces will tell the story of organizational adaptability, crucial to understanding LEF leadership.

2. Collaboration and relationship-building. LEF leadership also focuses heavily on collaboration and relationship-building. Because these organizations are intended to serve a permanent role in their communities, LEF leaders seek to develop high-quality connections between different sectors of the community, particularly the schools and the community in which they reside. Some LEF founders even implied that these relationships were the most important contribution LEFs make to school reform. Investigating factors that contribute to the quality and longevity of these relationships may help PEN support LEFs in this important work. In addition, the larger question of why this work is so central to LEFs should be explored further.

3. Inclusiveness of LEF leadership and community-building. Studying leadership prompts questions about the racial and class representativeness of LEF leaders, including LEF boards of directors. As mentioned, the executive director survey findings reveal a disparity between characteristics of LEF leaders and the communities they serve. Furthermore, inclusiveness is also an issue when LEFs claim to be engaging "the community." Which community sectors are included? Which are left out? Documenting trends in inclusiveness, and attempting to identify causes of trends, is critical to a full understanding of the community-building mission of all LEFs.

4. Opportunities and obstacles. Organizations need opportunities to make positive change in their communities. LEF leadership, characterized by flexibility and collaboration, serves to guide the complex interactions between the LEF and its environment, where those opportunities emerge. Some opportunities lie waiting to be found; others are forged through joint efforts. In any case, they are seized and become the foundation for future endeavors. Obstacles, too, can be created or simply encountered. A true test of leadership is how an organization deals with serious challenges. Further study of patterns in maximizing opportunities, and neutralizing obstacles, would be useful to PEN and to LEFs. 
These four preliminary research themes relate directly to how LEF leadership interacts with the local, state, and national contexts in which the LEF operates. For example, using adaptive leadership, the LEF leader reaches out to engage community stakeholders in dialogue about how to improve schools. Because LEF leaders tend to be focused on creating a sustained collaborative forum, this outreach tends to be ongoing, contributing to the development of a lasting relationship. The inclusiveness of the LEF's outreach efforts could be a useful yardstick for measuring the LEF leadership's commitment to equity and other issues. LEF leaders must be poised to take advantage of opportunities that arise, such as a grant opportunity from a national foundation.

As yet, we don't know if the cross-cutting themes are independent of the developmental stage of an LEF. However, future study of these themes ought to chart their influence across various developmental stages of a longstanding LEF. For example, an LEF may be founded by a board that does not adequately represent the community it serves. Over time, this issue may become an obstacle to key LEF programs and policies that serve the goal of full community engagement in school reform. Such a challenge may be addressed by an executive director, who could institute a new selection process for board members. Another example concerns financial capacity. The LEF leadership model embraces relationshipbuilding. In many cases these relationships result in increased financial capacity for the LEF. However, as funding opportunities shrink nationally and locally, new types of relationships will have to be forged to gain secure funding.

Amidst these variations, all LEF activities stem from leadership provided by the executive director, key staff, and the board of directors. In-depth exploration of LEF leadership will illustrate what is unique, and important, about the LEF "brand" of leadership. Already we have some clues. Stepping back from this research, certain values emerge. Leaders appear to exhibit:

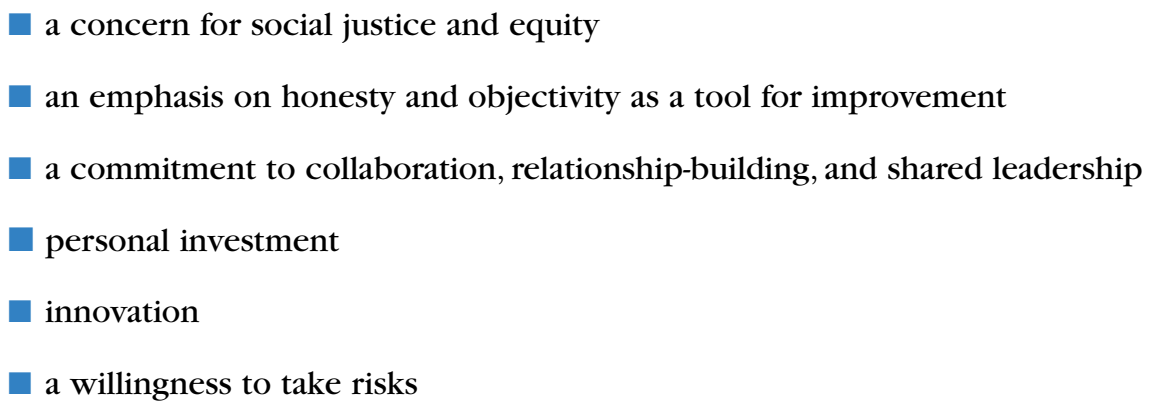

A better grasp of these values will enrich PEN's understanding of LEF leadership and underscore its contribution to education and community building. Given that PEN/PEF has played an important role in supporting LEFs, it is natural that the organization will want to identify patterns in LEF growth to guide future organizational development efforts.

To explore these issues across a wide variety of communities, a qualitative research method that utilizes rich narrative description should be employed. The story of a founder's experience, told through her own and her community's perspective, can be the source of an in-depth examination of the complex nature of LEF leadership. Because each story is so different, a case-study approach seems most appropriate. It will allow researchers to describe varied contexts and situations and ultimately discern crucial themes that more fully describe the work of LEFs in school reform. A good first step, then, might be to conduct a small number of initial case studies, starting, perhaps, with the early founders because preliminary research has already yielded useful themes to pursue. 
This deep-level analysis of one group of LEF leaders ought to be accompanied simultaneously by a more comprehensive data collection activity. For example, a follow-up to the first Urban Institute survey of executive directors could be administered. The purpose of a follow-up director survey would not be to gather in-depth information about leadership - for which case studies and interviews are better methods-but to assess several more general issues. First, the follow-up survey could help determine whether the themes being explored in the initial case studies resonate with current directors. Second, the follow-up survey could be used to define cohorts of interest for future case studies, such as "next generation" leaders or leaders of color. For example, in our interviews with founders, two former directors talked about how their LEFs were challenged to remain as productive once they left the organization. Documentation about how many current directors have faced the challenge of being a successor (or leaving and passing this on to the next director) could help PEN decide on priorities for its research.

Third, the follow-up survey could gather more detailed information about general findings from the first executive director survey, such as what LEF directors meant when they said they needed more time for "strategic planning." Fourth, a broad data collection activity would help PEN understand those examples of LEF leadership that do not fit the norm, particularly if these examples fail. The examples could be further studied through small-scale data collection activities, such as telephone interviews with leaders who have left LEFs. Finally, collecting data from all PEN directors may offset executive directors' concerns we heard about PEN's apparent tendency to focus attention on a core group of longstanding directors.

PEN has embarked on an important path: the creation of a working theory of LEFs as unique intermediary organizations. The literature on organizational change can contribute much to this inquiry. The research on education reform, tooparticularly the emerging role of intermediary organizations-has influenced and been influenced by LEFs. Perhaps most relevant, for "small organizations with big missions," organizational challenges will be paramount. Results from a wellplanned research agenda will guide PEN's future organizational development efforts and contribute more broadly to the literature on school improvement. 


\section{End Notes}

1 Although PEF was not intended to be a permanent organization, LEFs' need for a national support organization gave rise to a second three-year grant after the initial five-year grant ended. Renamed the Public Education Fund Network, this organization relocated to Washington, DC, in 1991, and in 1995 changed its name to its current title, the Public Education Network.

2 When this study was conducted, PEN included 59 LEFs. Currently PEN includes 77 LEFs.

3 See Raphael, J. and Anderson,A. (2001). The Public Education Network Study of Local Education Fund Leadership: Report on Baseline Survey Findings. Reported submitted by the Urban Institute to the Public Education Network. Washington, DC:The Urban Institute. All further references to survey results are derived from this document.

${ }^{4}$ Included in this discussion of founders are initial directors, who were brought in to lead the LEF after it had been founded.

5 Appendix A includes short summaries of each interview with an LEF founder.

6 See Appendix B for a copy of the protocol.

${ }^{7}$ Most of the founders interviewed held the position of LEF executive director for 10 years or longer.Thus, they provided information about issues that extended beyond the early founding period.

8 Based on 2000 member survey data collected by PEN.

9 See the Summary of Presentations (1999). NEA EXPLORE: Reassessment of Support for Arts Organizations-Life Cycles and Critical Junctures of Organizations, http://arts.endow.gov/explore/Colloquia/lifecycles.html. Note we focus on an ideal LEF life cycle and do not include "unsuccessful" stages such as "decline" in this figure.

\section{|| Bibliography}

Bergholz, David. 1992."The Public Education Fund.” In Teachers College Record.93(3): 516-522.

Chrislip, David D. and Larson, Carl E. 1994. Collaborative Leadership: How Citizens and Civic Leaders Can Make a Difference. San Francisco: Jossey-Bass.

Heifetz, Ronald A. 1994. Leadership Witbout Easy Answers. Cambridge: Harvard University Press.

Lawrence-Lightfoot, Sara. 1999. Respect: An exploration. Reading, MA: Perseus Books.

Nanus, Burt and Dobbs, Stephen M. 1999. Leaders Who Make a Difference: Essential Strategies for Meeting the Nonprofit Challenge. San Francisco: Jossey-Bass.

Puriefoy, Wendy D. 2001. "Local Education Funds: Powerful Partnerships for Public Schools." In Constituency Building and Advocacy for Education Reform: A Collection of Seminar Papers. Convened June 24-25, 1999. New York:The Open Society Institute.

Raphael, Jacqueline and Anderson, Alissa. 2001."The Public Education Network Study of Local Education Fund Leadership: Report on Baseline Survey Findings." Report submitted to the Public Education Network. Washington, D.C.: Urban Institute.

Useem, Elizabeth. 1999. From the Margins to the Center of School Reform:A Look at the Work of Local Education Funds in Seventeen Communities. Washington, D.C.: Public Education Network. 


\section{Appendix A: Founding Director Interview Summaries}

\section{Charlotte Advocates for Education Charlotte, North Carolina}

In the early 1990s, business leaders formed Charlotte Advocates for Education (CAE), an LEF meant to support a nationally recognized education reformer just hired to serve as the district superintendent of Charlotte schools. The group of business leaders, with a power company president at the fore, convened a board of directors, whose members recruited Corinne Allen for executive director. Although Allen had limited experience in school reform, she had directed a nonprofit and had significant community leadership experience. She also had the advantage of learning about the Public Education Network during one of Wendy Puriefoy's visits to Charlotte to speak about local education funds. According to Allen, Puriefoy provided her with direction and guidance and was critical to the development of the CAE.

CAE began by designing programs that supported the district's school improvement, such as providing teacher mini-grants and designing education programs suggested by the superintendent. But the group quickly transformed itself into a more independent reform agent. Within several years, in response to a vote altering how the school board got elected, CAE embarked on a large-scale study to learn how much the community knew about school governance and the potential effects of the election change. Working with a research consultant, CAE surveyed the public and conducted focus groups as part of its community assessment. Notably, these efforts revealed that less than 15 percent of the community even knew about the change and that few understood the critical role the school board played in school decisions.

The results of this study spurred a CAE-led public relations campaign called "Make Your Mark on the Board," to educate voters and help them make informed decisions. As part of this campaign, CAE ran television, radio, and newspaper advertisements; held seven town meetings; distributed more than 50,000 brochures; and displayed posters throughout the community. It also provided professional development training to newly elected school board members. Throughout the project, CAE provided information to the public without advocating any particular position.

Information turned out to be a powerful tool. Just when the organization had begun "nibbling at the edges" of school reform, another event thrust CAE further toward center stage. Voters' surprising rejection of a school bond suggested that the district school board lacked public support. On investigation, CAE discovered that the public did not believe the school board was using existing funds effectively. Allen approached the district superintendent with this information and suggested that CAE bring in independent auditors to review district spending practices. The auditing team, which ultimately found that the community's suspicions of the district were unfounded, disseminated its findings to the community. In this way, CAE secured its reputation as an objective provider of needed information. It also enabled the district to eventually get the bond passed.

Through these two projects, CAE expanded its role as a "critical friend" of the district. For instance, it conducted training workshops to inform school board candidates of their responsibilities and periodically assessed and publicized public opinion on the quality of the school board's work. More important, according to Allen, the LEF's role as a key player in local education issues allowed it to foster good relations with the subsequent superintendent.

Allen believes having a board of recognized civic and corporate leaders is critical to an LEF's longevity. She credits CAE's board for giving the LEF credibility and enabling it to grow quickly, with adequate funding. 


\section{Forward in the Fifth}

Berea, Kentucky

In the mid-1980s, U.S. News and World Report revealed that Kentucky's fifth congressional district ranked last in the nation for percentage of adults with high school diplomas. In response to this report, Earle Wallace, a native of the fifth district, commissioned the Mountain

Association for Community Economic Development

(MACED) to investigate the condition of education in the region. MACED recommended the creation of an umbrella organization to work to improve the educational attainment of citizens of the fifth district. In 1986, by providing funds and supplying its own staff members, MACED gave birth to Forward in the Fifth (FIF). Initially, FIF was led by its board chair on a volunteer basis. In 1991, Ginny Eager, a MACED employee, was hired as a paid executive director.

From the outset, FIF served school districts in 27 counties. (It currently serves 59 districts.) The sheer size and geographical reach of the organization's territory presented challenges for maintaining close contact with all of the districts and schools. To address this issue, FIF created local affiliate branches to carry out its work. FIF also organized a meeting with all district superintendents; at this meeting, Eager presented FIF as an ally in hopes of gaining trust and support from these districts. When area superintendents identified a need to increase student attendance, FIF responded and launched an attendance incentive program, offering schools cash prizes and designing an outreach program for parents. According to Eager, it was important for the LEF to take action on whatever need the superintendents discussed at that first meeting. "We were willing to do anything that showed them our value," she says.

Throughout its activities, FIF has maintained its role as an independent support for schools. In addition to the attendance program, FIF adopted the mini-grant model and initiated a field-trip program that the districts could not afford. Like many LEFs, FIF received a Library Power grant, which helped them gain a much higher profile in the community. Eager claims FIF is "still considered the foremost authority on libraries" because of this grant. When asked to speculate on the reasons for her organization's longevity, Eager explains that the schools were simply "very needy."

A pivotal point for FIF came in 1990 through the enactment of the Kentucky Education Reform Act, a statewide school reform law. Because schools were consumed with the changes required by this law, FIF shifted its focus to assist them with the reform. For example, as schools began to implement site-based management, FIF provided training on group skills for counsel members. The LEF also held informational forums for the public explaining the law and its consequences.

About five years into its development, Eager and her staff realized they needed to use more effective organizing skills. The members took advantage of an opportunity to participate in three years of community organizing training through a southern grassroots leadership development initiative. The training proved useful to local affiliates, and Eager and her staff soon realized that the training would be even more valuable to low-income parents to "break the cycle" of school dropouts. Thus, FIF has begun to target low-income families with parent training workshops.

FIF is also trying to affect a cultural change to improve educational attainment. Eager explains that Appalachia is an isolated region, with few opportunities to learn about other cultures. To address this issue, and to begin to break down the "rigidly institutionalized racism" in the region, FIF is developing a program to enable teachers to travel to other states and countries. 


\section{Lincoln Public School Foundation}

Lincoln, Nebraska

The Lincoln Public School Foundation (LPSF), founded in 1989, works with a school system that has won national awards for its academic outcomes. Barbara Bartle, the executive director, sees LPSF's role as a catalyst, sparking public interest in the value of education and guarding against complacency.

LPSF was modeled after a successful foundation at the University of Nebraska. Its initial goals were to solicit funds from alumni and conduct campaigns to create endowed funds. The then-superintendent and the school board organized a steering committee that led to LPSF's founding, helped in part by a large gift from a former teacher. In addition, an outstanding educator and community leader helped lay the groundwork for the fledgling organization.

When Bartle became executive director, the initial founders' gift campaign was nearing completion. To help move LPSF to the next phase, she asked a former president of the University of Nebraska, and of its foundation, to serve on the board. He jumpstarted the LEF's development efforts and gave the already strong board even more expertise. Bartle also sought to broaden the LEF's vision beyond fundraising, which led her to PEN. A year later, LPSF joined, and since then, the scope of LPSF has widened.

For example, Library Power and the Comprehensive School Health Grant, both large initiatives fostered by PEN, gave LPSF an identity beyond fundraising, the organization's primary focus for five years. These initiatives emphasized community involvement and included valuable training and technical assistance. In addition, at around the same time, the board learned that 75 percent of the community did not have children in public schools. This surprising news, and the new efforts in the large PEN initiatives, challenged Bartle and the board to think harder about how to better engage the public in education. The LEF's first independent step in this direction was to conduct a study with Gallup on the community's challenges and priorities for the school system. The results of that study continue to shape LPSF's efforts. In addition, LPSF is working with a communications consultant to strengthen its public dissemination efforts.

Tensions emerged as the LEF expanded beyond fundraising to activities promoting public engagement around educational issues. The LEF board and the school board of education are working together to develop strong communication channels to secure this new relationship. LPSF's development is worth watching carefully to see whether and how an LEF can make the transition from fundraiser to public advocate. Bartle's leadership style may help: She works best "behind the scenes," showcasing the role of her board rather than drawing attention to herself-and indeed, she genuinely thinks the board has been the key to LPSF's success. It is likely that her style, and the LEF's financial stability, will enable it to withstand the challenges ahead. 


\section{Los Angeles Educational Partnership}

Los Angeles, California

In the early 1980s, like many cities on the East Coast, Los Angeles was struggling to deal with overcrowded, underfunded schools, an influx of immigrant students speaking different languages, and public frustration with court-ordered busing. Peggy Funkhouser and others, many affiliated with CORO, a leadership training program, began to think about applying a neighborhood redevelopment model to public education. These discussions led to the formation of the Los Angeles Education Partnership (LAEP), an LEF with a 15-member board of directors made up of corporate and foundation leaders and led by Peggy Funkhouser.

Funding came fairly easy to the new LEF.The California Roundtable had helped to pass the first State school reform legislation in 1983. David Bergholz and PEF provided a \$200,000 incentive match. Los Angeles corporations also contributed funds. In addition, while speaking in foundation circles, Bergholz suggested that national foundations, such as Rockefeller and Carnegie, explore the state of education in Los Angeles. Because of this early interest and several large multiyear grants, LAEP at first "had more money than it could spend," according to Funkhouser.

The new LEF had other advantages: links to a leadership network, a small but strong corporate leadership base, the then-superintendent's desire for outside help to assist the district in improving schools, and an open-door policy with the LEF. More important, the superintendent understood how important it was for the new organization to be independent of the district school board. For this reason, he did not seek to put district representatives on the LEF board.

Still, the large, complex challenges in Los Angeles schools required LAEP to negotiate its role with care.Though committed to helping the district address the significant challenges it faced, the board was careful in the beginning to make sure LAEP was not perceived as a "mouthpiece" for the district. Also, because of the size of Los Angeles, the board took time to determine the most strategic use of its limited funds. In its early years, with the superintendent's blessing, the LEF built its credibility on effective work with networks of teachers and schools. The Partnership saw its role as investing its "venture capital" in the research and development of effective reform strategies and as a "hothouse for innovation." Later, with larger grants, the board made scaling up a priority and focused on extending the LEF's proven programs to other school sites. The adequacy of funding led LAEP to address more issues than it had originally intended. Eventually, the multifaceted work provided experience across many issues and led to a more comprehensive school-based approach, which resulted in a grant from the New American Schools for the Urban Learning Centers design.

An engaged, highly competent board of directors gave Funkhouser the support she needed to raise funds and communicate the importance of education to the city's leadership. Funkhouser judges the success of LAEP by the community's increased engagement in educational issues; the expanded media coverage of education, from nonexistent to frequent front-page features and evening news stories; and the greater number of people engaging in productive dialogues with educators. 


\section{Mon Valley Education Consortium McKeesport, Pennsylvania}

As a result of declines in the steel industry, the Mon Valley region in southwestern Pennsylvania suffered devastating job losses between 1975 and 1985. The region lost half its population, and its public schools suffered a dramatic decline in resources. It was in this context that David Bergholz of PEF met Linda Croushore. A former teacher and principal in the McKeesport School District, Croushore was passionate about public school reform and expressed a strong desire to do something for the public schools in her community. Bergholz, through PEF, provided $\$ 5,000$ in start-up funds, which Croushore used to raise $\$ 36,000$, the first budget for the McKeesport Public Education Fund.

Working alone and on a voluntary basis, Croushore borrowed a telephone and began calling around the community to learn what people had to say about public education. She convened a board, recruiting members demographically representative of the community, and met to discuss what the organization could do to improve education. Croushore also received support from Jane Burger, then director of the Pittsburgh Education Fund, and Gerri Kay, also from PEF.

From the beginning, Croushore and the board thought "forward" to the organization's legacy. They envisioned the LEF helping communities place public education in "a premier place of importance" by focusing on children as the future of the economy. To reach this goal, the organizers decided that the LEF needed to carry out a public-information and community-engagement agenda.

For instance, like most fledgling LEFs, the McKeesport LEF adopted the teacher mini-grant program. However, Croushore added a unique twist: by requiring that grant recipients gain publicity for their awards, through newspapers or radio spots, the mini-grant program also functioned as a "hook" to engage the community in conversations about education issues.

Because of the mini-grant program's popularity, fewer than two years after its inception, the LEF was approached by 19 other local school districts eager to join. The LEF incorporated these districts and renamed itself the Mon Valley Education Consortium (MVEC). Croushore is proud of the relations MVEC has maintained with most districts, despite the constant changes in leadership across the now 25 districts.

According to Croushore, MVEC saw its role as being an advocate for public education. She and her board believed that building capacity in schools and communities would lead naturally to school improvement. For example, early in its development, MVEC took advantage of a unique opportunity to affect school climate. The LEF responded to a state-issued request for proposal for a lead teacher initiative. While the initiative was intended to pull select teachers out of schools to train them to become leaders, Croushore says this approach did not align with how she and others conceptualized leadership training. Thus, instead, MVEC designed school renewal teams made up of teachers selected by their own peers. The teams were charged with determining which issues in the school were key and to develop ways to address them. Their philosophy, according to Croushore, was "if you create the right culture in schools, leadership will emerge." By abandoning the topdown approach, and viewing all teachers as potential leaders, the program produced a core of committed people truly engaged in school improvement.

Although MVEC was conceived with funding from the Ford Foundation, Croushore acknowledged that gaining funding beyond the seed money was difficult. Fortunately, with the help of Bergholz and others, Croushore was able to convince foundations in nearby Pittsburgh that its redevelopment depended on the success of the Mon Valley region. These foundations continue to be an important source of support-financial and otherwisefor the LEF. In addition, through fundraising, MVEC has been able to build a small endowment. 


\section{Nashville Public Education Foundation}

Nashville, Tennessee

By the mid-1980s, after two tumultuous decades of desegregation court orders, public confidence in the Nashville public schools had waned. In 1987, Annette Eskind, a school board member and well-known member of the community, donated $\$ 1$ million and founded the Nashville Public Education Foundation (NPEF) to rejuvenate public support for the school system. The LEF was modeled after the vision supported by the Ford Foundation: teacher mini-grants served as the centerpiece of the initial work, and a strong board of directors represented key decisionmakers from the community.

After a year of running the organization with volunteers, Eskind, as board chair, hired Debby Gould to be NPEF's first executive director. While Gould did not have education experience, she had worked in nonprofits and had a good understanding of the community. Gould's primary responsibilities included overseeing the minigrant program and grant writing, while Eskind continued to build relationships and establish the LEF's credibility.

From its inception, NPEF functioned as a support for a district troubled by sometimes erratic, confusing court orders. The LEF never took on a project without initial district buy-in. Gould describes the LEF's purpose as "filling in niches" for the district by identifying needs and providing the expertise and resources to address those needs. Trends in teacher requests for minigrants helped NPEF recognize teachers' needs; next, NPEF realized that principals could also benefit from mini-grants to address schoolwide efforts to increase parental involvement.

Gould also initiated several innovative programs, including one in which a local radio station advertised the district's need for musical instrument donations for its schools.

In 1990, NPEF received a \$1.2 million Library Power grant. The grant allowed the organization to foster more systemic, district-wide change. NPEF promoted collaborative teaching practices, introduced the concept of self-guided student learning, and ultimately led the district to adopt its best practice recommendations. Equally important, the grant had a significant effect on the LEF's growth. Soon it was pushing the district to take responsibility for sustaining new programs. For example, a decade after creating and publishing a booklet instructing parents on how to prepare their children for kindergarten, entitled "Now I'm Five," NPEF passed the responsibility on to the district. Gould continues to emphasize NPEF's role as a "catalyst," with NPEF's relationship with the school system becoming increasingly systemic. Currently, for example, the LEF directs the Principals' Leadership Academy, a collaborative effort with the school system and Peabody College of Vanderbilt University.

In addition to building a relationship with the school district, NPEF has had to negotiate its role in relation to other nonprofit organizations in the community. Gould says the LEF has always collaborated with other organizations in projects and that part of this collaboration involves delineating each group's particular role-not only to avoid stepping on toes, but also to maximize efficiency. NPEF, for instance, has decided not to send volunteers directly into schools because another organization has taken on this role. 


\section{Paterson Education Foundation Inc.}

Paterson, New Jersey

The Paterson Education Foundation (PEF) was established in 1983 in the first round of grants from the Ford Foundation. Irene Sterling served as executive director for the first three-and-a-half years, then left to pursue other ventures. But the two executive directors succeeding her had difficulties, and by 1990 the LEF had severe financial problems. At the same time, the state had begun monitoring the Paterson school district, a first step toward state takeover.The LEF board of directors was deadlocked on whether to support or oppose state operation. It asked Sterling to come back and help determine PEF's role in this stressful political environment."This was a turning point," says Sterling. Although she had been advised in the past to keep the LEF out of the political arena, the organization had to take a stand or it would have no voice-and no role to play.

When the state subsequently took over the Paterson school district, Sterling focused on how the LEF could support the eventual return to local control."Within a year of the takeover, PEF started asking what had led to takeover, and what could be learned to make sure it doesn't happen again," according to Sterling. Although many of the original board members left, Sterling found new, younger replacements willing to support the schools as they moved through the takeover. Now, she is proud that PEF is the only community-based organization that the state commissioner consulted to describe the status of state control of the district.

At the time of the takeover, Sterling began supplying data to counteract the political hearsay that had always circulated in the schools. With a board election coming up, the LEF saw the opportunity to inform the public about the board's function and how to run as a candidate. Without taking a position on a specific candidate, PEF provided the public with information on the specific candidates who ran.

Sterling has continued to work with the community. She has tried to help Paterson residents see that the schools needed to improve and that their participation could make it happen. "We sought to change policy first by changing community values and attitudes," she says. For instance, a series of conversations about race and education were held involving more than 150 people, including parents, community agency staff, business leaders, and others not previously involved in education.

"We gave people a chance to hear and be heard," says Sterling. From these talks she wrote up a community agenda in 1999, which charged the community with taking responsibility.

According to Sterling, PEF is the only organization in Paterson that "has something to say about education." More important, it is viewed by the community as a key player in education reform. Her staff and board have been recruited to perform statewide work on the Abbott reforms in New Jersey and have been asked to train other communities in their work.

Sterling attributes her ability to effectively lead a troubled organization in a troubled school district to several characteristics. She says she is "a good translator of other people's language" and that she can effectively communicate with diverse groups of people. She also has "imagination," meaning she can envision how schools and communities can be different, and she recognizes that changing schools requires changing communities. 


\section{Los Angeles Educational Partnership}

Los Angeles, California

Community members concerned about education funding following the passage in 1991 of a statewide property tax limitation founded the Portland Schools Foundation (PSF) in 1995. At about the same time, the state legislature passed major education reform legislation calling for higher student performance. Realizing the city's public schools needed the support of a "strong organized community voice" to deal with challenges to the largest urban school district in the Northwest, the superintendent and a well-connected downtown lawyer and parent leader convened a group of key players in the community to create a grassroots, independent, school-advocacy organization.

After a year of organizational meetings, the board of directors hired Cynthia Guyer, a founding member of the board, as executive director. A parent whose children attended public school, Guyer became interested in the problems facing the city's public schools. She had a strong background in philanthropy and nonprofit fundraising that included experience as a board chair and a director of development in several nonprofit organizations. The LEF opened its doors in January 1996 with a budget of $\$ 25,000$.

Following the recommendation of her board, Guyer began learning about Portland public schools' major challenges by interviewing 100 public opinion leaders. These interviews allowed her to better understand the pressing educational issues in the community and to announce to PSF's formation to key community members.

The interviews revealed that school funding was the most pressing issue, and that grantmaking around reform would be futile given that the district was facing a \$25 million cut that year.Thus, the board determined the LEF's first action would be to effect funding changes. Guyer and the board began two major campaigns: the first raised money to rehire the $300+$ teachers laid off by the spring budget cuts; and the second coordinated a public march calling for stable funding for schools. Both campaigns were "extraordinarily successful," according to Guyer. In only eight weeks, PSF raised \$10 million to rehire 200 teachers in a one-time-only large "bake sale" for the city's schools, and 30,000 people participated in the largest march of its kind in Oregon's history. This "really rattled the cages of the state legislature," says Guyer. Because of this event, the LEF was able to work directly with the mayor and the Portland business community to build a statewide public education lobbying organization, the Coalition for School Funding Now, to advocate for stable and adequate school funding.

While PSF mobilized immediately around political issues, it began to implement other types of school improvement/ community engagement initiatives after Guyer discovered the Public Education Network. By acquiring new ideas and contacts through the network, the LEF developed two major initiatives: a comprehensive school reform grant program and a funding initiative to support parent and community involvement, particularly in high-poverty school communities. The superintendent strongly supported both of these programs.

Relations with the leadership of Portland Public Schools remained positive from the LEF's initial founding in 1995 through 2000. After the departure of the first superintendent in 1997, the founding Board President of the LEF ran for the Portland School Board, won, and immediately became the Chair of the School Board. From 1997 through 2000, the LEF was invited to join the district leadership in several major efforts.

Over the past two years, LEF relations with the school district have weathered stress and strain. In mid 2000, the School Board president's term ended and the LEF found itself without a key ally and "champion." A year later, the school district superintendent also left, and since that time, the Portland School Board has been unable to recruit a permanent successor. 


\section{Public Education and Business Coalition \\ Denver, Colorado}

In 1983, Susan Zimmermann and her law partner Gail Klapper started a part-time project to bridge the gap between public schools and the private sector in Denver, Colorado. Like other urban centers in the early 1980s, Denver suffered from school desegregation, increased segregation between city and suburbs, and a growing gap between rich and poor. Zimmermann and Klapper believed the business community had a role to play in schools. To better define this role, the two women used a small grant from a nonprofit organization to bring together a wide range of stakeholders-school superintendents, business people, teachers, community leaders-to discuss the issues and determine what could be done. The Public Education and Business Coalition (PEBC) grew out of these early conversations. From the outset, it was a multidistrict effort that included Denver and several suburban school districts.

For the first couple of years, Zimmermann and Klapper provided approximately 20 hours a week pro bono work to get the organization off the ground. In 1985, the two founders were approached by David Bergholz and Gerri Kay, who helped them secure a grant from the Ford Foundation to support the work of PEBC. With that grant, the women were able to dissolve their law firm.

Zimmermann became the executive director of PEBC, while Klapper remained active on the board of directors. The LEF attracted grants from local foundations and corporations and created a strong board of directors that included business leaders, school superintendents, the head of the teacher's union, and community representatives.

Over the years, PEBC began to expand its funding base through the provision of staff development services on a fee-for-service basis. (Initially, these services were underwritten with grants; however to sustain the services, PEBC had to adopt a fee-for-services model.) Business leaders and educators together identified areas to target for assistance. Improved writing instruction was the first area identified. PEBC responded by bringing in wellknown experts from universities around the country to provide workshops. It then brought on local experts to provide long-term staff development support to teachers. With limited funds, PEBC began by serving a small number of teachers, signing on only those who wanted the training and who made a commitment to attend workshops, to work with a staff developer in their classroom, and to participate in debriefing sessions. The constraint on participation made the programs seem more like a privilege to teachers, which increased demand. In time, PEBC focused more broadly on literacy instruction as a tool to improve students' writing skills and reading comprehension. The LEF added math and science staff development models later.

Notably, PEBC did not focus all its efforts on schools. The board recognized that systemic change in education had to come both from the bottom up-in programs targeted to schools and classrooms-and from the top down. To that end, PEBC also worked with the school districts' central offices. In one example, the LEF helped the districts deal with public criticism about their organizational structure by bringing in experts from local corporations to conduct management and efficiency studies. These studies produced constructive feedback about ways to make district operations more cost-effective and built valuable relationships between the business volunteers and educators.

Zimmermann's willingness to call up national experts and ask for advice, and to persuade them to contribute to PEBC's efforts, is part of what made her a pioneer in the LEF movement. Ultimately, this direct service work helped sustain PEBC. Zimmermann feels that all LEF directors should try to create a diversified funding base and not rely too heavily on foundation grants. 


\section{Washington Parent Group Fund}

Washington, DC

The Washington Parent Group Fund (WPGF) is one of the few LEFs that preceded grants from the Ford Foundation. Unlike other LEFs, WPGF's purpose focused on parents. Specifically, its goal was to empower parents by providing them with the resources, training, and voice to advocate for their children in public schools. To accomplish this mission, WPGF worked directly with parents at partner schools in Washington, DC.

Joy Majied became involved with WPGF as a PTA president and parent of a child with special needs in one of the public schools that partnered with WPGF. First, Majied served as a parent representative to the LEF and then became staff a year later. By the second year, she was hired as the LEF executive director. Having learned to advocate on behalf of her son and other parents whose children had special needs, Majied felt driven to use those skills to help other parents become stronger advocates.

Under Majied's leadership, WPGF initiated several programs, including a parent training institute and a training model workbook to provide parents with the skills needed to work effectively with schools and teachers. Parents not only benefited from WPGF's work, but they were also active participants in it. They worked directly with school staff, administration, and other parents and developed projects to improve students' learning opportunities and to foster good relationships between home and school.

The LEF shared terrain with Parents United, a sister advocacy organization that, unlike WPGF, addressed citywide education issues. The two groups differed in their strategies:WPGF advocated for change by serving a supportive, capacity-building function for parents and schools, while Parents United advocated for change at higher levels, often by suing the district.

Nonetheless, district support came fairly easily for WPGF. Majied attributes this ready support to WPGF's nonthreatening, bottom-up approach and to her ability to present WPGF's position as "child first," "fair," and "open” to considering more than one strategy. Gaining the trust of the district allowed Majied access to policy people inside the system. From this position, she and WPGF were able to urge the district to adopt policies helpful to parents. For instance, when local restructuring teams were introduced to the district, WPGF was instrumental in ensuring that parents were well-informed before the teams were implemented.The efforts of WPGF ultimately resulted in the creation of a district-level parentinvolvement office to carry on many of the projects started by the LEF.

Under Majied's leadership, WPGF had a long track record of consistent funding in the city. Many funding connections came through the Washington Lawyers' Committee on Civil Rights, the central organization in the founding of WPGF and Parents United. By including parents in funder meetings and events, Majied hoped to foster relationships that would develop parents' capacity for advocacy and remain viable beyond her time at the helm, which ended in 1996. 


\section{Appendix B: Founding Director Telephone Interview Protocol}

\section{Founding and Early Years of LEF}

1. Please tell me about the founding of your LEF.

- Impetus/need/initial vision

- Key players

- Highlights of founding/sequence of events

- Funding sources

- Staffing

- Knowledge base

- Board

- Establishing legitimacy/credibility

2. How were you involved in the founding?

- Initial contact

- Other activities at time

- Motivation

- Relationship to/role in developing initial LEF vision

- Challenges and how you addressed them

3. What were the milestones (pivotal points) in your LEF's early development? What was your role during these times (e.g., initiated, reacted to, recognized them)?

- Key events/transitions/achievements-anything that changed the landscape and/or your LEF's ability to make change

4 What programs did your LEF bring in initially? Why did you pursue these, and what was the value-added? [go beyond mini-grants]

5. When would you say your LEF was truly established (i.e., institutionalized to some degree)? Why? What indicators are you drawing on?

6. How did you personally address the key challenges to sustaining your LEF in its early years?

7. Did you do things that contributed to your LEF's longevity? If yes, what? [Probe only if necessary: fundraising, risktaking, motivating others]

8. An LEF's success is not defined only by whether it has created many well-funded programs. In areas besides programming, what did you do- and how - that demonstrate your success as a founder and leader of a new LEF? [Greater public engagement; more coordination between agencies and stakeholders; greater access to information]

9. What role did you play in the key relationships that affected your LEF's development in its early years? [Your key helpers/collaborators (inside or outside your LEF)] 


\section{LEF Organizational Issues}

9. What do you feel were your unique qualifications for the role of founding director?

10. Was there anything you needed to learn to be an LEF director? How, and how well, did you learn it?

11. What was your leadership approach initially? How has it changed over the time you've been a director? [Decisionmaking]

12. When did you bring on additional staff? Why?

13. Who was driving the initial LEF activities: you, the Board, Board chair, a team effort?

14. How much time did you personally devote to director activities in the early years? Did that change over the years? If yes, why?

15. Please characterize your relationship with the school district in your LEF's early years. Did it change? If yes, why and how?

16. How did the superintendent(s) perceive your LEF? Why? How do you think he/she felt about you and your role?

17. Imagine a continuum for LEFs. At one end, the LEF serves as an agent of the district, at the other, as an agent of the community. Initially, where was your LEF on this continuum? How has this changed? [be sure to explore validity of this question with respondent]

18. How have things changed for directors since your LEF's founding?

19. If you could pass on a lesson to today's directors, what would it be?

\section{LEF Context}

20. Please confirm your LEF's founding year:

21. Please describe the community served by the LEF at the time of founding (e.g., socio-economic class, race/ethnicity of members, involvement of parents/community in public schools).

22. What was the community's perception of public education when the LEF was founded? Who were some key players at that time? [Probe only if necessary: quality of schools, teachers, district administration, degree of engagement in reforms, sufficiency of reforms, etc.]

23. Were there other issues related to schools, e.g., teacher strikes, shortages, high staff turnover, relationships within districts/schools, specific reforms pursued by the district? 


\section{Background of Respondent}

24. Previous experience-nonprofit, education, private

25. Educational achievement (highest degree and in what area)

26. Where living (in the community served by LEF at time of founding?)

\section{Questions about Research Methods}

27. How difficult was it for you to remember details about the founding of your LEF? Can you think of any artifacts or approaches that would help you recall events better and in more detail (e.g., timeline, minutes)?

28. To whom would we talk today to shed light on your role as founding director?

29. Availability for future data collection activities... 
